МЕЖДИСЦИПЛИНАРНЫЕ ИССЛЕДОВАНИЯ

INTERDISCIPLINARY RESEARCH

\author{
УДК 811(470.67)
}

DOI: 10.12731/2077-1770-2017-4-334-347

\title{
СРАВНЕНИЯ С ЭТНОКУЛЬТУРНЫМ КОМПОНЕНТОМ В ПРОИЗВЕДЕНИЯХ А. АБУ-БАКАРА
}

Алиомарова Г.И., Семиляк В.И., Магомедова Л.А.

В статье анализируются сравнения с этнокультурным компонентом в произведениях известного дагестанского писателя $A$. Абу-Бакара как один из способов создания художественных образов и выявления национального мировидения автора.

Цель статьи - на основе анализа произведений данного автора выявить роль сравнений с этнокультурныл компонентом как важной составляющей идиостиля писателя.

В рамках данного исследования авторами был использован описательно-аналитический метод, предусматривающий непосредственное наблюдение анализируемых языковых фактов с последующим обобщением полученных результатов.

На основе проведенного исследования авторами выявлено, что сравнения с этнокультурным компонентом в произведениях А. Абу-Бакара служат ярким оченочно-характеристическим средством в портретном описании персонажей; конкретизируют эмоционально-психологическое состояние героев; выполняют описательно-изобразительную функиию в пейзажных зарисовках.

Сравнения с этнокультурным компонентом являются одной из особенностей идиостиля А. Абу-Бакара.

Область применения результатов: Методика анализа и полученные результаты исследования могут быть использованы при изучении роли сравнений с этнокультурным компонентом в идиостилях других 
художников слова, в практике преподавания лингвистического анализа текста, стилистики русского языка, спецкурсов и спецсеминаров.

Ключевые слова: сравнение; этнокультурный компонент; экзотизм; топос; эпитет; метафора; лексема.

\section{COMPARISONS WITH ETHNOCULTURAL COMPONENT IN THE WORKS BY A. ABUBAKAR}

\section{Aliomarova G.I., Semilyak V.I., Magomedova L.A.}

The article analyzes the comparison with ethnocultural component in the works of the famous Dagestan writer A. Abu-Bakar as one of the ways of creating artistic images and identify the national worldview of the author.

The purpose of the article is to reveal the role of comparison with ethnocultural component as a main component of the writer's idiostyle on the basis of analysis of A. Abu-Bakar's works.

In this study, the authors used a comparative-analytical method, involving direct observation of the analyzed linguistic facts with the subsequent generalization of the obtained results.

On the basis of the study, the authors revealed that the comparisons with the ethnocultural component in the works by Abu-Bakar are considered as a vivid estimating characteristic means in the portrait description of characters, spelling out in detail the emotional and psychological state of the characters, as well as performing the descriptive and visual function in the landscape descriptions.

The scope of the results: method of analysis and the findings of the study can be used to study for comparisons with ethnocultural component in other writers' works, in teaching linguistic text analysis, stylistics of the Russian language, special courses and seminars.

Keywords: comparison; ethnocultural component; exotism; topos; epithet; metaphor; lexeme.

В настоящее время существует ряд работ, в которых с разной степенью полноты изучается сравнение как важный элемент идиостиля 
известного дагестанского писателя А. Абу-Бакара (И.Я. Алиханова, А.М. Вагидов, Т.Ю. Султанова). Однако целостного и последовательного лингвистического анализа использования А. Абу-Бакаром художественного приёма «сравнение» до настоящего времени не проводилось, что обусловливает актуальность данного исследования.

Научная новизна исследования определяется тем, что впервые представлен анализ сравнений с этнокультурным компонентом в произведениях А. Абу-Бакара, определены их особенности и выявлена роль в формировании индивидуального стиля.

Теоретическая значимость заключается в том, что результаты исследования расширяют и углубляют современные представления о сравнении как одной из доминант идиостиля писателя, а также уточняют сведения о процессах формирования и репрезентации художественного сравнения.

Сравнение принимает непосредственное участие в создании образа, но при этом одни сравнения сами по себе представляют образ, а другие, не являясь образом, только способствуют его созданию. Сопоставляя признаки двух явлений для пояснения одного другим на основе сходства признаков, писатель использует сравнения в общей системе изобразительных средств, то есть сравнения в совокупности с другими языковыми приёмами способствуют возникновению более конкретного, более точного представления об изображаемой действительности. По мнению Б.В. Томашевского, сравнение основывается не столько на сходстве самих предметов, сколько на сходстве авторского отношения к сравниваемым предметам [12, с. 32].

Сравнение как одна из языковых деталей создания целостного представления о явлении, действии, характере занимает в творчестве А. Абу-Бакара немалое место.

А. Абу-Бакар - признанный мастер художественного слова, один из лучших стилистов в дагестанской многонациональной литературе советского периода. Язык его произведений отличается яркой изобразительностью и образностью. Изобразительность А. Абу-Бакара - это не только следование традициям, которые сложились в литературе, но и новое слово в развитии языка прозы Дагестана. Писатель обновил поэтику прозы: никто до него не использовал так 
широко эпиграфы, яркие эпитеты, сравнения, фольклорные произведения и их элементы (сказочные персонажи, притчи, легенды, пословицы и поговорки), узуальные обороты, реминисценции [5, c. 10]. А. Абу-Бакар красочно описывал обряды, этнографические детали. Многообразны используемые им топосы, очень свежи пейзажи. Во всем этом проявилась орнаментальность стиля повести, что было необычно для даргинской прозы.

Орнаментальная поэтика прозы А. Абу-Бакара проявляется в поэтично описанной жизни горцев. Писатель рассматривает и оценивает мир с субъективной точки зрения: одной из граней авторской позиции здесь является идеализация внешнего мира. Романтизация повествования достигается путем очень активного использования автором поэтических описаний природы, многочисленных этнографических деталей, фольклорных элементов, включения в повествовательную ткань экзотизмов, поэтических изобразительно-выразительных средств.

Тропы, употребляемые в прозаических произведениях А. Абу-Бакара, отражают модель мира мастера художественного слова. Проза писателя насыщена образными средствами, содержащими в своей структуре этнокультурный компонент. Сравнения с этнокультурным компонентом стали одной из узнаваемых неповторимых черт индивидуальной манеры А. Абу-Бакара. Характер выбора предметов для сравнения отражает национальные особенности языковой картины мира писателя.

Основой оригинальных авторских сравнений является неожиданное сопоставление двух предметов, относящихся к разным понятийным сферам. Создавая портретные описания своих персонажей, пейзажные зарисовки, писатель использует в составе сравнения наименования предметов быта народов Дагестана, расширяя таким образом тематическую соотнесённость предмета и образа сравнения и создавая нетривиальные индивидуально-авторские сравнения.

Функции сравнений с этнокультурным компонентом в текстах художественных произведений А. Абу-Бакара многообразны и зависят от места их положения в структуре художественного целого. В портретных описаниях они выполняют оценочно-характеристическую функцию, субъективно-познавательную - в отражении точки 
зрения героев, в пейзажных зарисовках - описательно-изобразительную, функцию конкретизации в описании эмоционально-психологических состояний персонажа.

В качестве предмета сравнения А. Абу-Бакар использует лексические единицы, представляющие наименования предметов быта народов Дагестана: кинжал, бурка, папаха, чурек, кувшин, котёл, грецкий орех и др.

К примеру: «Издали Луарсаб мог показаться молодцом, но только не вблизи. Овальное, приплюснутое сверху и снизу лицо, большие бегающие глаза, взметнувшиеся будто в удивлении брови и вечно ехидная усмешка в уголках заячьих губ, $\boldsymbol{a}$ уши точь-в-точь две ручки сасанидского котла. И этот шар без намёка на шею поставлен на что-то квадратное. Да и ростом бедняга не удался» [1, с. 39].

В данном примере писатель с помощью сравнительной конструкции а уши точь-в-точь две ручки сасанидского котла сосредоточивает внимание читателя на характерной детали в портретном описании персонажа. Сравнение вносит национальный колорит в авторское повествование и значительно усиливает эмоциональную оценку в зрительном восприятии данного персонажа. При этом заметим, что фоновых знаний для понимания сути сравнения недостаточно даже у дагестанского читателя.

Сасанидские котлы были распространены на территории Дагестана - это полушаровидные и низкие котлы с несколькими ручками-кольцами. Следовательно, форма уха персонажа была довольно далека от идеальной, а сравнение ещё раз подчёркивает приземистость, приплюснутость во внешнем облике героя. При этом сравнение представляет особенности этнокультурного сознания писателя, которое отражает особенности национальной культуры, истории и ментальности.

В прозе А. Абу-Бакара региональные реалии, которые писатель использует в качестве предмета сравнения, повторяются и становятся основой для создания нового образа. Например, повторяется в качестве предмета словосочетание сасанидский котёл в составе сравнения при описании высокогорного аула:

«Жители Зангара считают своим Багдадом родной аул. Среди высоких гор есть одна пониже, похожая на опрокинутый сасанидский 
котел. Гору эту обтекают два рукава реки Варачан, и географ скорее назовет ее островом, омываемым водами горного потока. На этом густо заросшем лесом островке и расположился древний аул Зангар, увенчанный двенадцатиметровым минаретом старой мечети, с которой уже давно не звучал призывно-протяжный голос муэдзина» [3, с. 75].

Основой для сравнения горы с сасанидским котлом является общий признак реалий - малый по высоте. С помощью сравнения писатель обращает внимание читателя на невысокую гору и создаёт национальный колорит.

Сравнения в тексте художественных произведений - это прежде всего яркое средство оценки реального мира через призму экспрессивно-эмоционального восприятия. С помощью оригинальных сравнений автор формирует субъективную оценку (положительную или отрицательную) созданных им персонажей. Подчеркивая изящество и стройность юных горянок, автор сравнивает их с узким кувшином:

«Свет струился от гладких плеч, высокой груди с бронзовыми пуговками, узкой, как у кувшина, талии, округлого живота» [3, с. 274].

Чтобы усилить эмоциональную положительную оценку, создаваемую посредством сравнения, писатель вводит в структуру сравнения такую деталь бытового предмета, как узкое горлышко, например:

«Да, что правда, то правда природа милостиво одарила Вардо. Стройная, гибкая, ловкая с тонкой, как горлышко кувшина, талией, она с ума сводила мужчин» [1, с. 22].

В следующем примере писатель в портретном описании использует относительное прилагательное сувлекетский, которое вносит не только национальный колорит в сравнительную конструкцию, но и усиливает степень эмоционально-экспрессивной оценки, подчёркивая совершенство и хрупкость героини. Деминутивный суффикс -ышк- в лексеме горльпико реализует в данном контексте значение «меньший по объёмным параметрам - высоте, габаритам [10, с. 137-138] и усиливает экспрессивность данной сравнительной конструкции:

«Серминаз - девушка из моего аула, смуглая горянка, хрупкая и стройная, как узкогорлый сулевкентский кувшин, с черными, как ночь, глазами, от взгляда которых становится светлее на моей душе, 
с черными, как смоль, густыми волосами, спадающими на плечи тяжёлым потоком. Линии ее отточены, как будто лепил ее великий мастер вопреки всем запретам правоверных» [5, с. 220].

Заметим, что гончарные изделия из дагестанского аула Сувлекент славились функциональностью, тонкостенностью и лёгкостью, а водоносные сосуды - узким горлышком - не только по всему Дагестану, но и далеко за его пределами.

Для любой национальной культуры значима такая понятийная сфеpa, как еда. Важная роль в пищевых традициях дагестанских народов принадлежит изделиям из муки: хинкал, курзе, чурек, чуду (пирог) и др.

Традиционным хлебом у народов Северного Кавказа является чурек. Ахмедхан Абу-Бакар сопоставляет с чуреком различные реалии окружающего мира - солнце, человек. Например:

«Сейчас в подвале работает тат — горский еврей, которого кубачинцы именуют тоже Писахом. Это очень добрый и отзывчивый человек, круглый, как винная бочка, и румяный, как свежеиспеченный чурек, с крупным перстнем на левой руке - подарком какого-то завсегдатая» [5, с. 248].

В приведённом примере писатель сопоставляет Писаха с традиционным на Кавказе видом хлеба - чуреком. Основой для оригинального авторского сравнения является общий признак - цвет чурека и цвет лица персонажа. Посредством сравнения автор подчеркивает во внешнем облике персонажа красный цвет его лица.

В следующем примере в составе сравнительных оборотов писатель в одном контексте, описывая внешность, использует лексемы разных лексико-семантических групп кувшин и чурек, которые выступают как контекстуальные антонимы. В описании первой героини посредством лексемы кувшин автор фокусирует внимание читателя на ее стройности (точеную, как кувшин), создавая положительную субъективную оценку, а с помощью лексемы чурек, распространённой выразительным определением непропеченный, Абубакар подчеркивает недостатки внешности второй героини. Сравнительный оборот (как непропеченный чурек) актуализирует значение лексемы сырой («Тучный, с нездоровой полнотой разг.»), 
которая входит в синонимический ряд с лексемой рыхлый и усиливает негативную авторскую оценку, внушаемую читателю.

«А хороша ведь, чертовка. Надо быть таким медведем, как Синка-Саид, чтобы променять эту, как кувшин, точеную, на ту, рыхлую, сырую, как непропеченный чурек!.. И везет же в жизни таким беспутным... А женщины тоже: чем меньше их любишь, тем больше липнут!» [3, с. 273].

В произведениях А. Абу-Бакара в роли репрезентантов предметов сравнения выступают лексические единицы, представляющие собой наименования плодов фруктовых деревьев и плодово-ягодных кустарников, распространённых на территории Дагестана: персик, абрикос, яблоко, тёрн, кизил и др. Например:

«А девушка, между прочим, была удивительно хороша. И на колючке, говорят, цветок растет. Кто бы подумал, что у такого отца такая дочь. Белолицая, полненькая, румянощекая, Зейнаб была что персик в зелени листьев: возьми кончиками пальцев, надкуси и не только губы, вся душа нальется шербетом. Но берегись, не приведи аллах с косточкой проглотить, застрянет в горле [6, с. 89].

При этом в состав сравнения писатель вводит эпитеты, выраженные относительными прилагательными, указывающими на место, где выращивают вышеназванные плоды: хунзахский персик, цудахарские яблоки. Упоминание аулов Дагестана, где выращиваются фрукты вносит не только национальный колорит, но и является своеобразным эталоном качества. В сознании читателя рождается пресуппозиция: самый лучший, самый яркий, самый сочный. В результате авторское описание какого-либо объекта приобретает не только новые краски, но и приращение нового смысла. Приведём примеры:

«Когда мы вошли во двор, хозяйка сняла платок, и я увидел, что она молода и красива. Я загляделся на ее свежее лицо с пушистыми, как хунзахский персик, щеками, с пухлыми, резко очерченными губами и прямым носом» [5, с. 384];

«Во дворе копошилась наседка с выводком, и семеро ее цыплят издали походили на выкатившиеся из корзины цудахарского торговца спелые абрикосы» [5, с. 386]; 
«Месяц, похожий на ломтик чеченской дыни, поднялся над Тарки-Тау» [6, с. 18].

В произведениях А. Абу-Бакара в роли репрезентантов предметов сравнения также выступают лексические единицы, представляющие собой наименования животных, как домашних животных (кошка, баран, овцы, ягнята, конь и др.), так и диких (снежный барс, тур, горный волк, лиса, сайгак др.). Например:

«Мне город казался похожим на равнодушного ко всему буйвола, что лежит в грязи и медленно жует бесконечную свою жвачку» [6, с. 242];

«Ночь была ничем не примечательна, если не считать синего-пресинего неба и звезд, которые висели на этом атласе так низко, что казалось, будто кто-то погладил хребты гор, как гладят кош$\kappa \boldsymbol{~}$, и это искры из кошачьей шкурки. И луна на небе была такая же неповторимая, как моя Серминаз, и так же стыдливо прятала лицо под тонкой вуалью...» [5, с. 265];

«Он увидел, что Бахтина молодая, как месяц над степью, стройная, как камыш, легкая, как сайга» [2, с. 7];

«Часа два метался по комнате Хажи-Бекир, как раненый медведь» [5, с. 323].

Особое значение на Кавказе имеет оружие. Оружие - это признак достоинства и мужественности горца. С оружием в руках горец защищал свой очаг от врагов, совершал набеги, оружие сопровождало горца с момента рождения до его смерти. Неотъемлемой частью мужского костюма и символом достоинства на Кавказе был кинжал.

В качестве предметов сравнения используются лексические единицы-наименования видов холодного и огнестрельного оружия, распространённого на Кавказе, в том числе характерного только для Дагестана.

В произведениях А. Абу-Бакара нетрафаретным образным средством становится лексема кинжал: «Месяц, похожий на кривой кинжал, будто рубится с чёрными тучами, высекая всё новые и новые искры молний» [6, с. 7].

В данном примере автор использует в качестве предмета сравнения - существительное, называющее специфическую реалию 
быта дагестанцев - кинжал. В основе сопоставления двух объектов окружающей действительности лежит общий признак - изогнутая форма клинка кинжала. Сравнительная конструкция похожий на кривой кинжал становится основой для введения в текст новой сравнительной конструкции будто рубится с чёрными тучами, высекая всё новые и новые искры молний. В основе сопоставления данной сравнительной конструкции лежит функция кинжала как холодного оружия - клинок может наносить рубящие удары.

В результате употребления двух сравнительных конструкций при описании небесного тела создаётся осложнённый образ. Образ сравнения представлен двумя разновидностями: образ-предмет - кинжал и образ-ситуация, выраженный глаголом рубится, актуализирующим сему «сражаться холодным оружием» в составе сравнительной придаточной части. Союз будто, вводящий сравнительную придаточную часть, обозначает приблизительное сходство, и поэтому сравнение воспринимается как условное, что подчёркивает его выразительность.

В следующем примере: «Куда и зачем несется всадник в черном башлыке? Кто знает? Похоже, только сам он да и аллах в небе, который, как видно, смилостивился над ним, раз осветил ему дорогу и, разогнав тучи, пронес над его узкими плечами дождь и теперь вот стелет впереди путь прямой, как выемка на лезвии кинжала» $[6$, c. 10$]$.

В основе сопоставления реалий лежит форма желоба, который оружейники делают на лезвии кинжала для уменьшения веса и усиления прочности клинка. В качестве основания сравнения выступает имя прилагательное прямой, указывающее на качество предмета сравнения. В данном контексте у качественного прилагательного прямой актуализируется сема «ровно идущий в каком-нибудь направлении, без изгибов» [9, с. 628].

Как показывает проанализированный материал, грамматический статус сравнений, используемых писателем разнообразен. Это может быть слово (как сайга, чечевица), словосочетание (горный волк, цудахарские яблоки) предложение (как будто лепил ее великий мастер вопреки всем запретам правоверных): 
«Горы Чика-Сизул-Меэр. Цепь горных вершин, похожих на шляпки амузгинских гвоздей на подкове. Во впадине этой подковы и находится старый аул Чиркей, а все это место называется «Гнездом Орла» [4, с. 305];

«Это ее (Асият - курсив наш) я видел купающейся под водопадом. Пухленькие, пунцовые губы, большие, похожие на бездонные ключи, глаза, тонкие брови и родинка-чечевица на шее» [2, с. 81].

Сравнение может выражено различными грамматическими способами: лексическим - посредством лексем с семантикой сравнения (похожий, подобный, напоминает), прилагательными, вторая часть которых является стандартизированным показателем сравнения (-видный, -образный, -подобный) или указывает одновременно на объект и основание сравнения (-ногий, -лицый, -носый); морфологическим - с помощью сравнительной степени прилагательных и наречий, словообразовательными аффиксами, синтаксическим (сравнительный оборот, придаточное сравнения). Вводятся сравнительные конструкции посредством союзов как, будто, словно, точно, прилагательного похожий и др. Наиболее употребительными в прозе Абу-Бакара являются сравнения, вводимые в повествование с помощью семантического союза как, который используется для выражения реального сравнения.

Таким образом, этнокультурная специфика сравнений А. Абу-Бакара проявляется в выборе предметов и явлений для создания образов сравнения и даже способов выражения сравнения. Специфическое национальное видение мира отражается в семантике сравнений, связанной с особенностями растительного и животного мира, географическими особенностями, спецификой культурно-хозяйственной жизни народа. Сравнения выполняют важные выразительно-изобразительные, смысловые и эмоциональные функции, являясь особенностью идиостиля писателя.

\section{Список литературы}

1. Абу-Бакар А. Манана: Роман. М.: Советский писатель, 1990. 480 с.

2. Абу-Бакар А. Опасная тропа: (Повести и рассказы). Махачкала: Даг. кн. изд-во, 1982. 448 с. 
3. Абу-Бакар А. В ту ночь, готовясь умирать... Повести и рассказы. М.: Современник, 1978. 288 с.

4. Абу-Бакар А. Солнце в «Гнезде Орла». М.: «Молодая гвардия», 1976. $320 \mathrm{c}$.

5. Абу-Бакар А. Пора красных яблок. Роман и повесть. М., «Современник», 1974. $432 \mathrm{c}$.

6. Абу-Бакар А. Тайна рукописного Корана. Исповедь на рассвете. М., «Советский писатель», 1972. 400 с.

7. Алиханова И.Я. Поэтика орнаментальной прозы Ахмедхана Абу-Бакара: автореф. дис.... канд. филол. наук. Махачкала, 2014. 22 с.

8. Вагидов А.М. Повесть А. Абу-Бакара «Опасная тропа»: проблемно тематическое и жанрово-стилевое своеобразие // Ахмедхан Абу-Бакар: Творческая судьба. Махачкала: ИПЦ, 2001. С. 22-25.

9. Ожегов С.И. и Шведова Н.Ю. Толковый словарь русского языка: 80000 слов и фразеологических выражений / Российская академия наук. Институт русского языка им. В.В. Виноградова. М.: ООО «ИТИ Технологии», 2006. 944 с.

10. Резанова 3.И. Функциональный аспект словообразования. Томск: Изд-во Том. ун-та, 1996. 164 с.

11. Султанова Т.Ю. О некоторых особенностях поэтики повести А. Абу-Бакара «Белый сайгак» // Поэтика дагестанской советской литературы. Махачкала, 1986. С. 112-120.

12. Томашевский Б.В. Краткий курс поэтики. М.; Л.: Гос. изд-во, 1929. $132 \mathrm{c}$.

\section{References}

1. Abu-Bakar A. Manana: Roman [Manana: A Novel]. M.: Sovetsky pisayel', 1990. $480 \mathrm{p}$.

2. Abu-Bakar A. Opasnaya tropa: (povesti i rasskazy) [Dangerous path: (novels and stories)]. Makhachkala: Dag. kn.izd-vo, 1982. 448 p.

3. Abu-Bakar A. Vtu noch', gotovjas 'umirat'... Povesti i rasskazy [That night, ready to die... Novels and short stories]. M: Sovremennik, 1978. 228 p.

4. Abu-Bakar A. Solnce v «Gnezde Orla» [The Sun in the "Eagle's Nest"]. M.: "Molodaya gvardiya", 1976. 320 p. 
5. Abu-Bakar A. Pora krasnyx jablok. Roman i povest' [Time of red apples. The novel and the story]. M., "Sovremennik", 1974. 432 p.

6. Abu Bakar A. Tajna rukopisnogo Korana. Ispoved'na rassvete [Mystery of the manuscript of the Quran. Confession at dawn]. M.: "Sovetskij pisatel", 1972. $400 \mathrm{p}$.

7. Alikhanova I. Ya. Pojetika ornamental'noj prozy Akhmedkhana Abu-Bakara [Poetics of ornamental prose by Akhmedkhan Abu Bakar]. Makhachkala, 2014. 22 p.

8. Vagidov A.M. Povest' A. Abu-Bakara "Opasnaya tropa" [A story by A. Abu-Bakar "A dangerous path": issue-thematic, genre and stylistic originality]. Akhmedkhan Abu Bakar: Tvorcheskaja sud'ba [Akhmedkhan Abu-Bakar: Creative destiny]. Makhachkala: IPTS, 2001, pp. 22-25.

9. Ozhegov S.I. and Shvedova N.Yu. Tolkovyj slovar' russkogo jazyka: 80000 slov I frazeologicheskih vyrazhenij [Explanatory dictionary of the Russian language: 80,000 words and phraseological expressions / Russian Academy of Sciences. The Institute of Russian language]. V.V. Vinogradov. M.: OOO „ITI Technologiyi“, 2006. 944 p.

10. Rezanova Z.I. Funkcional'nyj aspect slovoobrazovanija [The Functional aspect of word formation]. Tomsk: Izd-vo Tom. un-ta, 1996. 164 p.

11. Sultanov T.Y. O nekotoryh osobennostjah pojetiki A. Abu-Bakara "Belyj sajgak" [Om some features of the poetics of the novel "White antelope" by A. Abu-Bakar]. Pojetika dagestanskoj sovetskoj literatury [Poetics of the Dagestan Soviet literature]. Makhachkala, 1986, pp. 112-120.

12. Tomashevsky B.V. Kratkij kurs pojetiki [A short course of poetics]. M., L.: Gos. izd-vo, 1929. 132 p.

\section{ДАННЫЕ ОБ АВТОРАХ}

Алиомарова Гумай Исаевна, кандидат филологических наук, доцент кафедры теории и истории русского языка Дагестанский государственный педагогический университет ул. Ярагского, 57, г. Махачкала, Дагестан, 367003, Российская Федерация usaeva41@bk.ru 
Семиляк Валентина Ивановна, кандидат филологических наук, доцент кафедры теории и истории русского языка Дагестанский государственньй педагогический университет ул. Ярагского, 57, г. Махачкала, Дагестан, 367003, Российская Федераиия Artik0521@yandex.ru

Магомедова Лейла Абдулхакимовна, кандидат филологических наук, доцент кафедры теории и истории русского языка Дагестанский государственньй педагогический университет ул. Ярагского, 57, г. Махачкала, Дагестан, 367003, Российская Федерачия

\section{DATA ABOUT THE AUTHORS}

Aliyomarova Gumai Isaevna, Candidate of Philology, Associate Professor of the Department of Theory and History of the Russian Language

Dagestan State Pedagogical University

57, Yaragsky Str., Makhachkala, Dagestan, 367003, Russian Federation usaeva41@bk.ru

Semilyak Valentina Ivanovna, Candidate of Philology, Associate Professor of the Department of Theory and History of the Russian Language

Dagestan State Pedagogical University

57, Yaragsky Str., Makhachkala, Dagestan, 367003, Russian Federation

Artik0521@yandex.ru

Magomedova Leyla Abdulkhakimovna, Candidate of Philology, Associate Professor of the Department of Theory and History of the Russian Language

Dagestan State Pedagogical University

57, Yaragsky Str., Makhachkala, Dagestan, 367003, Russian Federation 